\title{
Etología de camélidos y arte rupestre de la Subregión río Salado (norte de Chile, II Región) ${ }^{1}$
}

Josefina GonZÁLEZ A. ${ }^{2}$

\begin{abstract}
RESUMEN
Este trabajo trata sobre un estilo de arte rupestre del Período Formativo Temprano registrado en la precordillera de la Subregión río Salado. El estilo, llamado Confluencia, se caracteriza principalmente por el detalle con que fueron retratados los animales, precisando actitudes y posturas que delatan determinadas actividades. A base de esto se intenta una analogía con un registro de actividades observadas en grupos familiares de vicuñas (Vicugna vicugna). El resultado muestra que hay ciertas actividades que fueron representadas, mientras otras fueron dejadas de lado sugiriendo que existe una coherencia interna dentro del estilo, que estaría necesariamente relacionada con el contexto sociocultural en el cual se desarrollaron.
\end{abstract}

Palabras claves: arte rupestre - etología de camélidos Período Formativo Temprano.

\begin{abstract}
This paper discusses the Early Formative Period rock-art style that was recorded in the mountains of the Salado river sub-region. The style, called Confluencia, is mainly characterized by the detail with which it portrays animals and the precision with which attitudes and postures reveal certain activities. On this basis, an analogy is made with a range of activities observed in vicuña family groups (Vicugna vicugna). The results show that certain activities were depicted while others were left aside, suggesting there was an internal coherence to the style, which is necessarily related to the sociocultural context in which it developed.
\end{abstract}

Key words: rock art-camelid ethology - Early Formative Period.

Recibido: febrero 2003. Manuscrito revisado aceptado: agosto 2003.

\section{Introducción}

Es un hecho que la mayoría de los motivos figurativos en el arte rupestre del norte de Chile son representaciones de camélidos. Estos últimos forman parte de una escasa variedad de grandes her-

1 Este trabajo fue realizado en el marco del Proyecto FONDECYT 1950101.

2 Providencia 2145, Depto. 602, Santiago. Email: jogandreu @yahoo.com bívoros que componen la fauna latinoamericana, donde sólo se encuentran tapires, pecaríes, ciervos y camélidos. Todos ellos suman en total 21 especies y de estos grandes mamíferos, los camélidos, con sus cuatro especies, son los animales que predominan y caracterizan al Area Andina.

La presencia preponderante del camélido como mamífero mayor en el medio ambiente andino fue apreciada en el pasado por su importancia económica. Su adaptación a los ambientes áridos y fríos del Area Andina, donde la agricultura no es posible, lo convirtieron durante momentos precerámicos en un animal que proveía de carne, cuero, hueso y lana. Más adelante con el pastoreo se agregó la capacidad de carga y el caravaneo, transformándolo con todo esto en un valor estratégico para la supervivencia y el desarrollo cultural. Con sus cuatro especies, la llama y la alpaca domésticas y la vicuña y el guanaco salvajes, el camélido es omnipresente en el registro arqueológico y en las representaciones rupestres de los Andes del sur.

Los estudios de arte rupestre del norte de Chile no se han limitado a la simple descripción de los camélidos, sino que se han preocupado también por la búsqueda de sus significados. Algunos consideran el arte como una práctica del ámbito mágico-religioso de la cultura donde la pintura sería una estrategia propiciatoria para el éxito de la caza o la abundancia del pastoreo (ver p.e. Niemeyer 1972; Van Kessel 1976). Otros perciben en las pinturas aspectos simbólicos de la cultura que las realizó, descubriendo en ellas la representación de mitos relacionados con la abundancia (ver p.e. Berenguer y Martínez 1989), o bien las consideran como un intento de reflejar el medio circundante, como en una naturaleza muerta o un paisaje (ver p.e. Le Paige 1958). Todos ellos, en mayor o menor medida, se han referido al arte rupestre en términos de su funcionalidad económica, social y religiosa en el mundo andino (ver Mostny y Niemeyer 1983). 
El presente análisis se enmarca dentro de una serie de trabajos ${ }^{3}$ que intenta abordar el arte rupestre desde un punto de vista en el cual la funcionalidad no es el eje en torno al cual se articula el ejercicio de comprensión. Entre estos, está la relación del arte rupestre con respecto al paisaje en que se encuentra inserto (Gallardo et al. 1999), la lectura semiótica de la organización de los elementos iconográficos (Mege, en prensa; P. González, en prensa), así como la relación entre los elementos de la iconografía rupestre y su contraparte artefactual (Montt, en prensa).

En el presente trabajo se intenta extraer, a partir de las figuras dibujadas, la coherencia que las articula entre sí. Partiendo de la base de que la cultura material, en este caso el arte rupestre, no representa directamente las cosas, los rasgos o los conceptos del mundo social, sino que ella se encuentra más bien ordenada de acuerdo a este (Shanks y Tilley 1987), se plantea que lo que está representado pictóricamente remite de alguna manera al mundo social, en este caso a un aspecto de la relación del ser humano con los animales. Esta relación, que puede ser prosaica y simbólica al mismo tiempo (Tacon 1989), nace en la práctica cotidiana de la convivencia y en el conocimiento de los animales que el ser humano va adquiriendo a través de ella.

Mediante una analogía entre las posturas en que están representados los animales en las pinturas con las actividades y comportamientos estudiados por la etología de camélidos, se propone abordar el arte rupestre a partir de los animales y sus características observables. En este sentido, este trabajo no pretende adscribir una función al arte rupestre del río Salado, lugar al que pertenece la muestra con la cual trabajamos, sino averiguar de qué manera este podría informar acerca del período cultural en que aparentemente fueron realizadas, el Formativo Temprano.

\section{Pinturas y contexto arqueológico}

Los paneles rupestres considerados en este trabajo se encuentran en la Subregión del río Salado, en la precordillera de la Segunda Región de Chile (Figura 1). Se trata de una zona de quebradas intermedias ubicada entre el desierto absoluto y la

Proyectos FONDECYT 1950101 y 1980200. alta puna, donde hoy en día es posible practicar el pastoreo de vega y tolar, así como la agricultura a nivel doméstico.

La distribución de los paneles del estilo Confluencia está circunscrita a aleros que se ubican en las paredes de las quebradas de la Subregión. Las excavaciones practicadas han mostrado ocupaciones adscritas tanto a momentos tempranos como tardíos de la región, lo cual permite suponer una utilización continua de estos aleros durante el tiempo, relacionada con actividades de caza y pastoreo. Este desarrollo podría estar acompañado por una variación estilística dentro del conjunto rupestre, dentro del cual se definieron tres estilos llamados: Taira/Tulan, Confluencia y Cueva Blanca (Gallardo et al. 1999). Los antecedentes recabados mediante investigación arqueológica muestran que Cueva Blanca, adscrito al Período Formativo Tardío (250 DC-500 DC) sucede a los estilos Confluencia y Taira/Tulán los cuales corresponden al Formativo Temprano (550 AC-250 DC) (Aldunate et al. 1986).

El universo de estudio está compuesto por paneles donde se encuentran representados animales, seres humanos, líneas y figuras geométricas. De los tres estilos mencionados más arriba, dos de ellos agrupan a la mayoría de las figuras de camélidos. El primero, Taira/Tulan, se distribuye en el sector precordillerano desde el tramo superior del río Loa hasta la quebrada de Tulan, ubicada al sur del Salar de Atacama (Berenguer 1995; Núñez 1994; Gallardo et al. 1999). Este estilo, compuesto por grandes figuras de camélidos y aves realizadas mayoritariamente mediante la técnica del grabado se superpone en varios paneles sobre figuras del estilo que aquí nos ocupa, denominado Confluencia. Este último se caracteriza por "formas donde hay un claro esfuerzo por representar la disposición, tamaño, forma y lugar de los miembros externos del cuerpo humano o del animal" (Gallardo 1996 Ms). En cuanto a los camélidos pertenecientes a este estilo, se trata de un grupo muy consistente por las semejanzas formales que comparten las figuras, debido a que están construidas a base de patrones de medidas similares. Por ejemplo, la relación entre el largo y el ancho de las figuras se agrupa consistentemente entre los 0 y $20 \mathrm{~cm}$ para el alto y entre $10 \mathrm{~s}$ 0 y $15 \mathrm{~cm}$ para el ancho. Asimismo, existe una relación consistente entre las medidas de las patas delanteras con respecto a las patas traseras, 


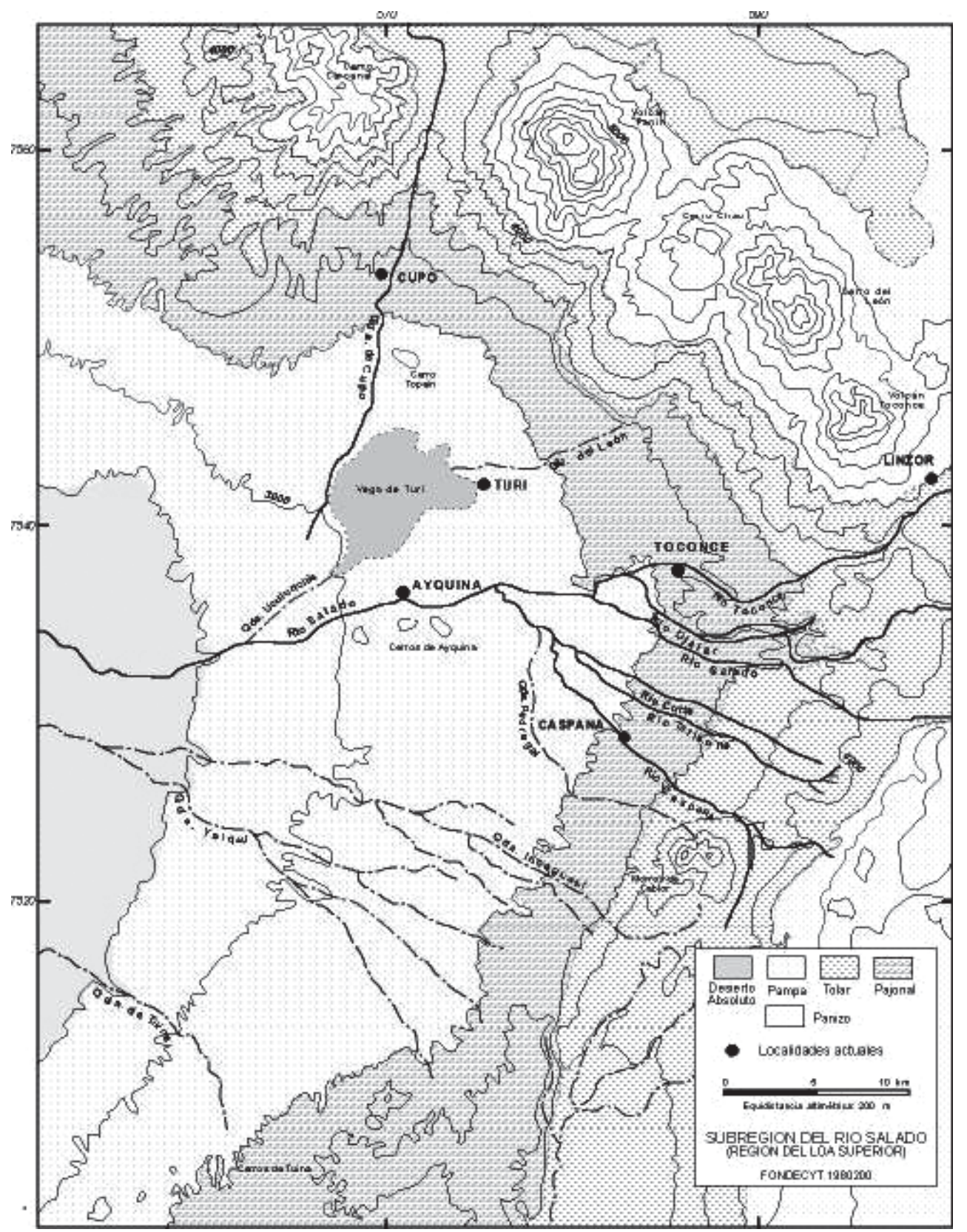

Figura 1. Mapa de la Subregión río Salado.

expresada en una relación de 2:1. En las figuras humanas, la homogeneidad de las medidas también está presente como, por ejemplo, en la relación del ancho de las caderas con respecto al ancho de las cinturas. El color predominante de las figuras de Confluencia es el rojo, combinado a veces con blanco o amarillo, y la técnica predominante es la pintura (Gallardo 2001). Cueva Blanca, por otro lado, representa un cambio ra- dical dentro del universo del arte rupestre del área ya que las formas de animales y seres humanos se vuelven rígidas, a la vez que disminuyen su frecuencia dando paso al predominio de las formas geométricas (Gallardo et al. 1999; Sinclaire 1997).

Las constantes que definen a las figuras del estilo Confluencia, tales como los patrones de construc- 
ción estandarizada, están asociadas con la representación de escenas que aluden claramente a actividades de caza, como ocurre en uno de los paneles del sitio 2-Loa 15, donde se observa una actividad de caza comunitaria. Esto, sumado a la ausencia del motivo clásico del caravanero que aparece en paneles del Período Tardío, cuando la domesticación de camélidos es un hecho comprobado (p.e. el sitio SBa-144, Berenguer et al. 1985), nos lleva a considerar por ahora como especies salvajes a los camélidos representados en nuestra muestra.

\section{Etología de camélidos}

La vicuña, una de las cuatro especies de camélidos, nunca ha sido domesticada. Existen testimonios de vicuñas recién nacidas que han sido cuidadas por familias de pastores, donde sólo han permanecido hasta una cierta edad en que se vuelven ariscas y problemáticas, momento en el cual son alejadas de la convivencia humana. Gracias a esto, sin embargo, es que han resultado adecuadas, junto con el guanaco, para el estudio del comportamiento y organización social de los camélidos, principalmente porque no han sido manipulados ni modificados por el ser humano como ocurre en las otras dos especies que son domésticas (llama y alpaca).

Estos animales se organizan formando una complicada sociedad cuando están en su hábitat natural. Ahí se dividen básicamente entre grupos familiares y grupos de machos solteros (Koford 1957), donde el primero de estos conforma la población sexualmente activa, compuesta por un macho dominante y defensor del territorio, con una o varias hembras, más las crías menores de un año de edad. Se caracterizan estos grupos por una jerarquización muy marcada y definida. El segundo grupo, compuesto por números cambiantes de individuos que pueden llegar en ocasiones hasta un centenar, no posee territorio y vagabundea, por lo tanto, a través de zonas marginales a los territorios familiares sin cohesión ni jerarquía. Estos últimos están compuestos en su mayoría por juveniles que han sido expulsados de sus grupos de origen y que durante el período en que conviven de este modo aprenden a ser adultos y a comportarse entre los machos, para luego formar familias (Franklin 1982a).

La convivencia familiar está regida por reglas de comportamiento que se revelan a través de la co- municación que establecen en la vida diaria. Esta comunicación está compuesta de gestos y movimientos corporales, además del olfateo, las vocalizaciones y los pasos, a base de los cuales ocurren los acercamientos y alejamientos dentro del grupo y entre los representantes de grupos que son los machos territoriales. En este sentido, los camélidos salvajes son una especie interactiva donde la agresión juega un rol comunicativo y creador de relaciones afectivas, a diferencia de otros animales que viven toda su vida unidos en compactas muchedumbres dentro de las cuales no se observa la creación de lazos ni la agresión marcada: "El vínculo personal, la amistad entre individuos, sólo aparece en los animales de agresividad intraespecífica muy desarrollada" (Lorenz 1980: 239). Todos estos actos comunicativos son recurrentes e identificables y, por lo tanto, discretos; es ahí donde la etología aplica su metodología de observación, registrando las pautas motoras en base a las cuales se comparan las conductas animales (Lorenz 1986).

\section{Figuras y etología}

Como ya se mencionó, las figuras animales del estilo Confluencia se caracterizan por el detalle con que se representaron las distintas partes del cuerpo. Cada animal forma parte de una escena, y dentro de esta cada uno tiene sus propios detalles particulares. En los animales vivos, es en las acciones comunicativas observables donde es posible realizar analogías con las representaciones rupestres. Por ejemplo, dentro de este lenguaje corporal, existen los llamados displays o posturas convencionalizadas, las posturas cotidianas y las distintas posiciones de orejas, cuello y cola (Franklin 1982 b). En la Figura 2 pueden apreciarse en la línea superior las posturas más comunes del cuerpo y al centro y abajo la progresión del ánimo agresivo cuando el animal experimenta un cambio de ánimo, graficado en el movimiento de las orejas y las colas (Franklin 1982a: 8).

A base de lo expuesto, para nuestro análisis se observó un total de 156 figuras del estilo, registrando en cada una de ellas las posiciones que presentan las distintas partes del cuserpo (Patas Delanteras, Patas Traseras, Cuello, Cola, Orejas, Cuerpo Anterior, Cuerpo Posterior), además de contabilizar el Movimiento y las Posturas. Como posturas se consideraron algunas de las referidas por Franklin (1982 a: 7), como displays tales como 

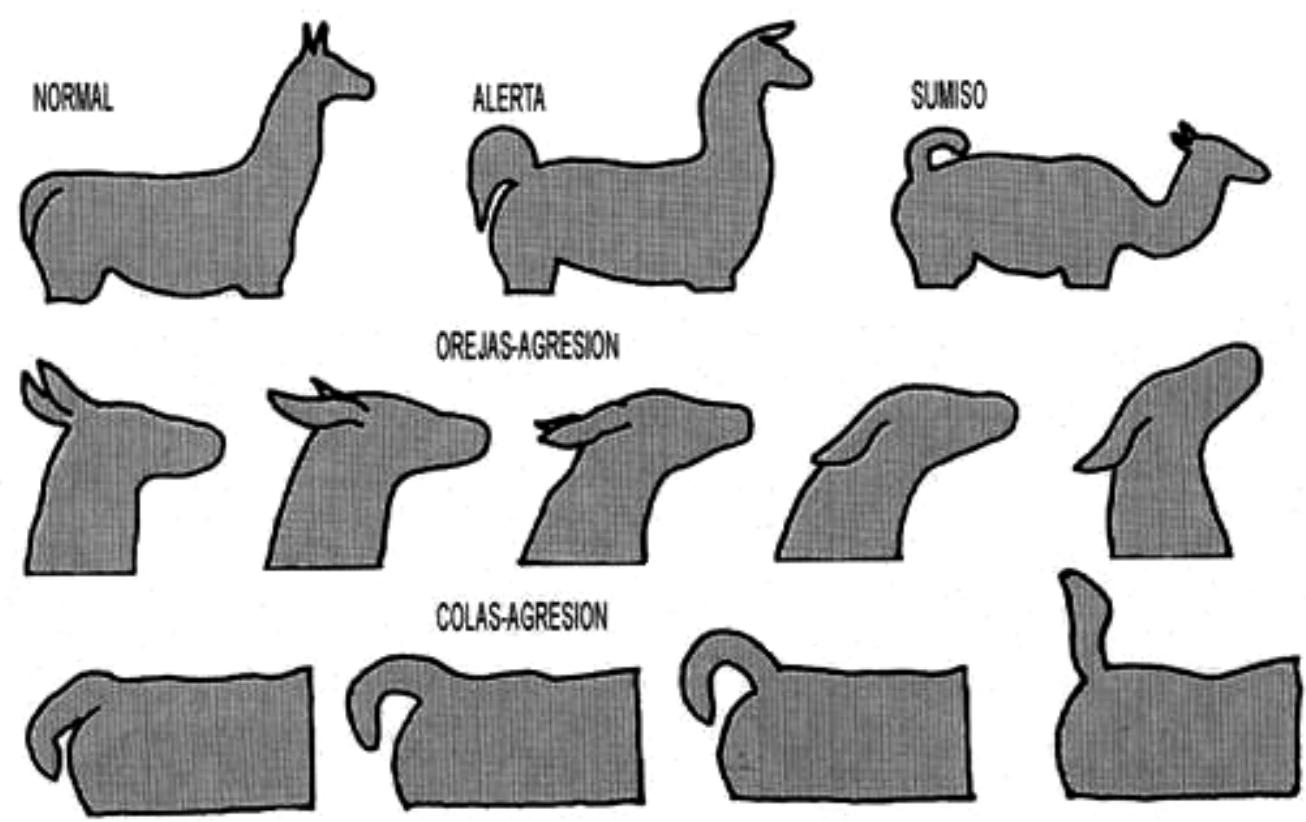

Figura 2. Modos de comunicación (Franklin 1982b).

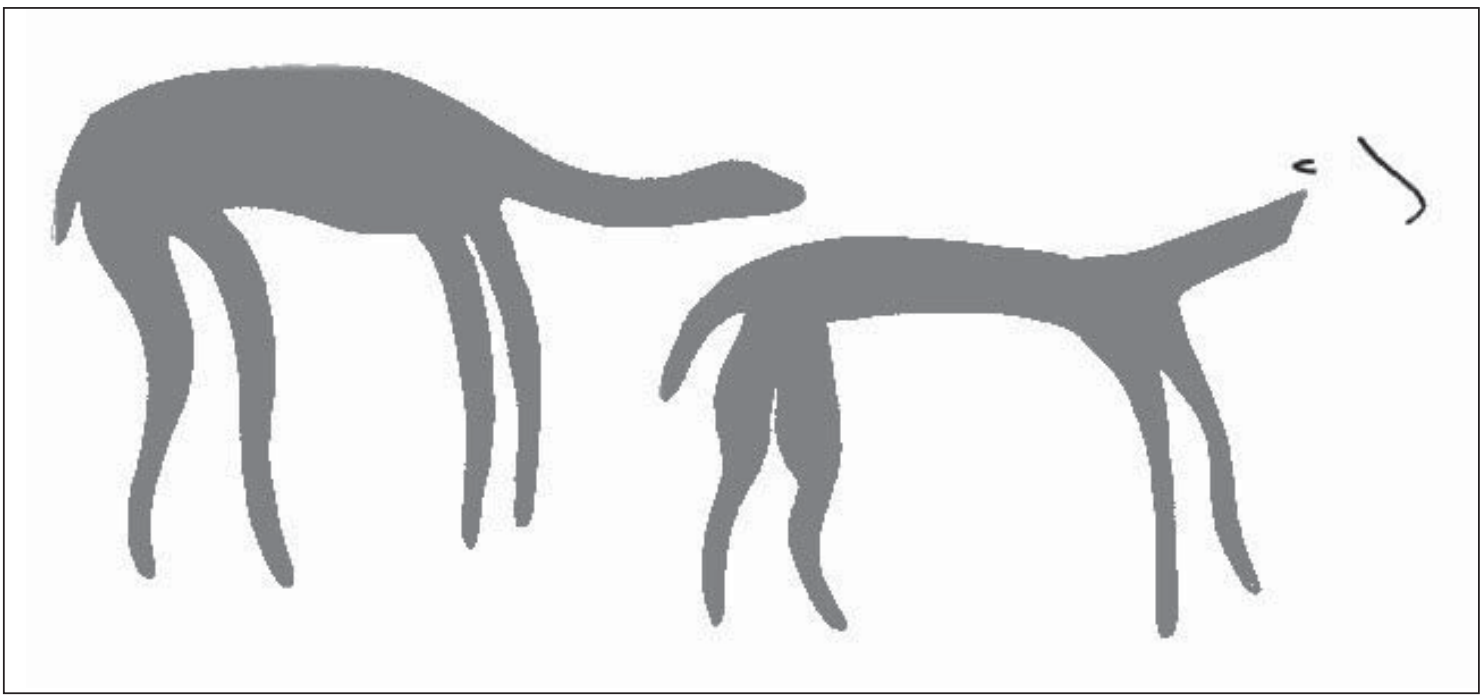

Figura 3. Cuello Horizontal.

la "Posición Perpendicular" (el macho se para en un ángulo de $90^{\circ}$ con respecto a su oponente), el "Cuello en S" (el macho, cerca de su límite territorial se para con las patas delanteras tiesas y el cuello ligeramente curvado), y la postura con el "Cuello Horizontal o Bajo la Horizontal" (que utilizan cuando se acercan o persiguen a un oponente, ver
Figura 3). Dentro de este atributo se incluyeron también las posturas de "Sumisión" (patas delanteras o traseras flectadas y cola curvada hacia arriba, ver Figura 4), de "Pelea" (el cuerpo erguido sobre las patas traseras enfrentando, o no, a un oponente, ver Figura 5) y "Alerta" (la cola levantada bajo la horizontal, el cuello erguido, las orejas 


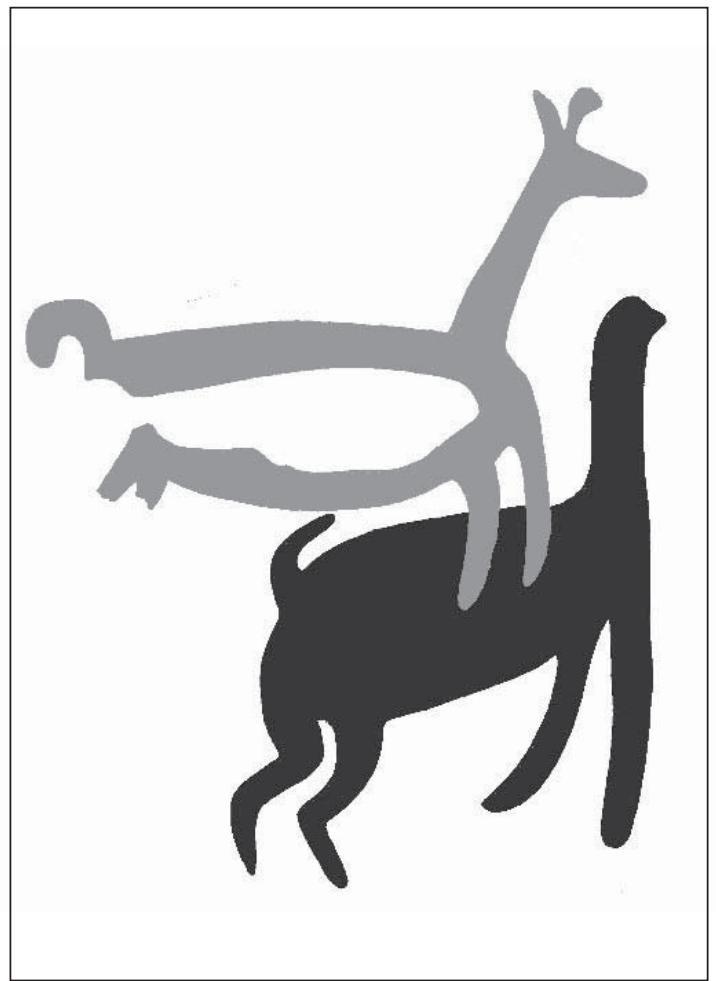

Figura 4. Sumisión (figura inferior).

hacia adelante) (Glade 1982). En cuanto al Movimiento, se consignaron las acciones de Saltar, Caminar, Correr, Agachar y Sin movimiento, de acuerdo a la posición misma de las patas así como la distancia de las patas, tanto delanteras como traseras, con respecto a la línea de suelo.

De los atributos contabilizados, sólo cuatro resultaron relevantes:

CUELLO, con cinco estados (Hacia Arriba, Hacia el Suelo, Hacia Atrás, Horizontal y Ausente), ocurre en la mayoría de los casos, en el estado Hacia Arriba (85.37\%). Este resultado es seguido por Hacia Atrás y Horizontal $(7.32 \%$ y $6.5 \%$ respectivamente), estados que indican molestia y agresión y que contrastan con el único caso de cuello Hacia el Suelo (que indicaría el acto de comer, ver Figura 6).

COLA, con cinco estados (Agresiva, Alerta, Sumisa, Normal y Ausente), ocurre en su mayoría en el estado Agresiva con un $60.2 \%$; luego siguen Alerta (19.39\%) y Normal (14.29\%), y por último, Sumisa está presente en un $6.12 \%$.

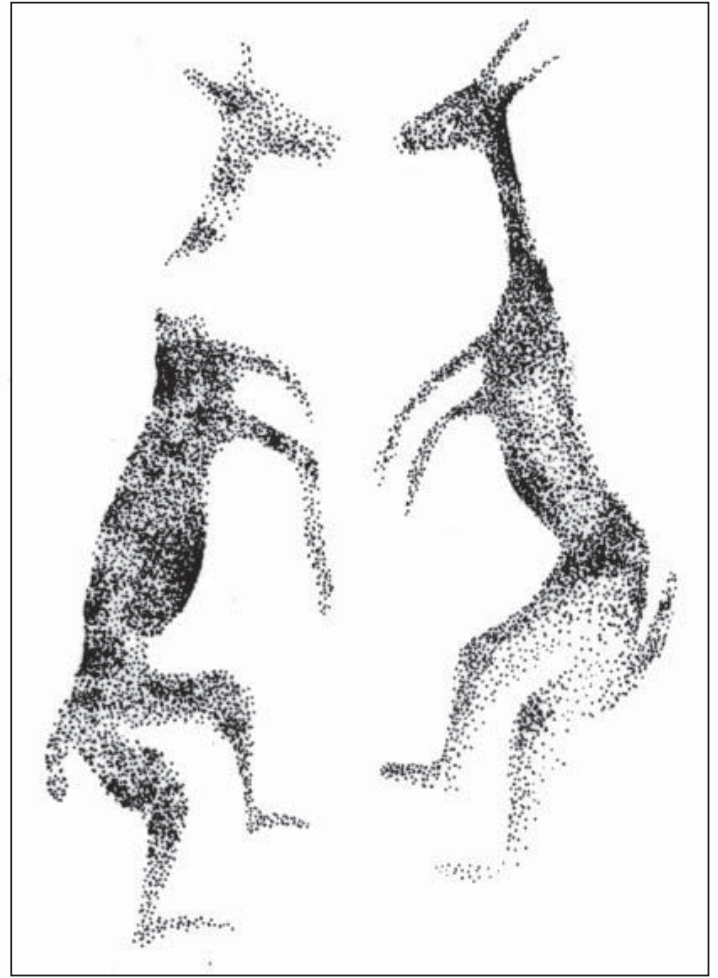

Figura 5. Pelea.

POSTURA, con seis estados (Sumisión, Alerta, Persecución, Pelea y Quietud, además de Incompletos), presenta el más alto porcentaje (54.83\%) para el estado Quietud; siguen Pelea con un $17.31 \%$, Sumisión con un $3.85 \%$ y Alerta y Persecución con $2.5 \%$ y $0.6 \%$, respectivamente. Los casos incompletos alcanzan un $2 \%$.

MOVIMIENTO, con cuatro estados (Saltar, Caminar, Correr, Agachar y Quietud), presenta el más alto porcentaje de presencia para Saltar, con un 23.22\%; esta cifra es seguida por el atributo Quietud, con un 21.29\%; Caminar y Correr presentan una frecuencia de $13.5 \%$ y $15.48 \%$ respectivamente, mientras Agachar sólo fue observado en un $6.45 \%$.

\section{Etología y arte rupestre}

Estos resultados, que muestran la actividad representada en las pinturas, fueron comparados con actividades reales observadas en la vida cotidiana de grupos familiares de vicuñas que habitan en el Parque Nacional Lauca (Segunda Región, norte de Chile). Esta información fue compilada en un 
censo practicado por CONAF (Glade y Cattan 1987), durante el cual se realizaron observaciones sistemáticas diarias por un período que abarcó desde mayo de 1981 hasta abril de 1982. Tal como se mencionó anteriormente, los estudios etológicos sobre camélidos han sido realizados en las especies silvestres debido a que en ellas no se han introducido las modificaciones de comportamiento a que han sido sometidas las especies domesticadas. En este sentido, sería interesante haber realizado la analogía con ambos tipos de condición de los animales; sin embargo, la inexistencia de estudios acerca del comportamiento en camélidos domesticados dejó esta tarea pendiente.

Las actividades registradas en el censo del Parque Lauca mencionado, fueron: Comer, Caminar, Echarse, Agredir, Revolcarse, Defecar-Orinar, Jugar, Correr, Observar, Mamar, Bañarse y Beber. Cada una de estas actividades fue observada por separado en Machos, Hembras y Crías dando origen a porcentajes de ocurrencia anual donde se observa que la actividad más recurrente es Comer, seguida por los movimientos efectuados para Caminar y Correr. La actividad Mamar, junto con Jugar, son las más frecuentes entre las crías desde su nacimiento hasta los seis meses de edad. Agredir destaca en menor medi- da respecto a estas últimas; pero, al igual que las ya mencionadas, sobresale entre el resto de las actividades observadas.

En las pinturas, haciendo una analogía, las actividades representadas son: Comer-Beber, Caminar, Correr, Observar-Alertar-Orinar, Mamar (ver Figura 7) y Agredir-Jugar. Las actividades compuestas, como Comer-Beber son el resultado de la dificultad de discernir a partir de la postura la actividad específica que se está llevando a cabo, y su composición está definida en base a las posibilidades que la adopción de la postura representa. La aparente contradicción que presentan, por ejemplo, Agredir-Jugar no es tal si se piensa que los juegos entre los juveniles son justamente ejercitaciones de conductas agresivas (Koford 1957). Del mismo modo, Observar-Alertar-Orinar son tres actividades para las cuales los animales adoptan posturas similares, y son, por otro lado, todas relativas al estado de alerta frente a un posible peligro.

Si se comparan las actividades representadas en el arte rupestre con las actividades presentes en el Parque Lauca se observa, en primer lugar, que de todas las actividades registradas en Lauca, en las pinturas están presentes Caminar, Correr, ComerBeber, Mamar, Agredir-Jugar y Observar-Alertar-

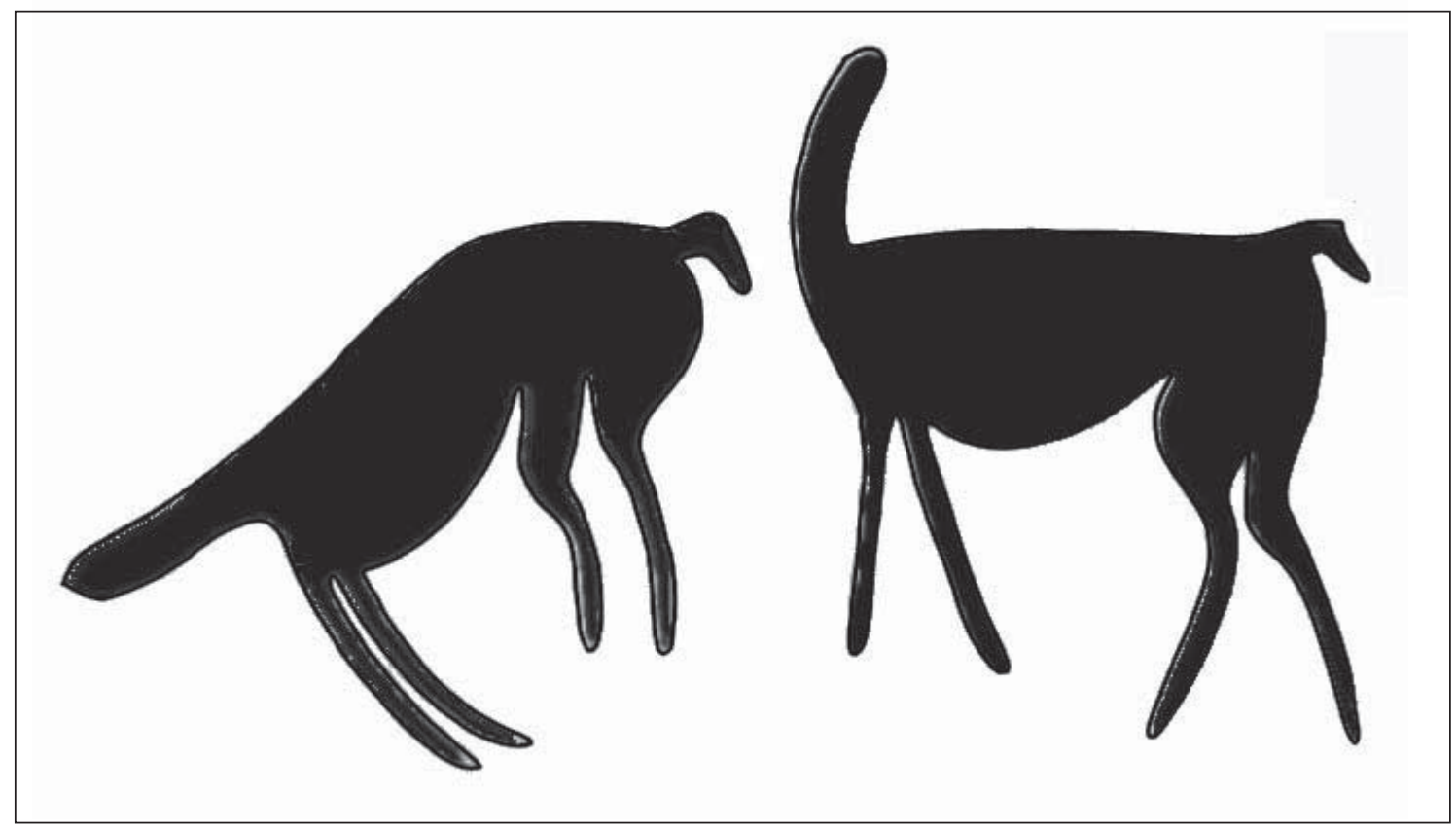

Figura 6. Cuello hacia abajo y cuello hacia atrás. 


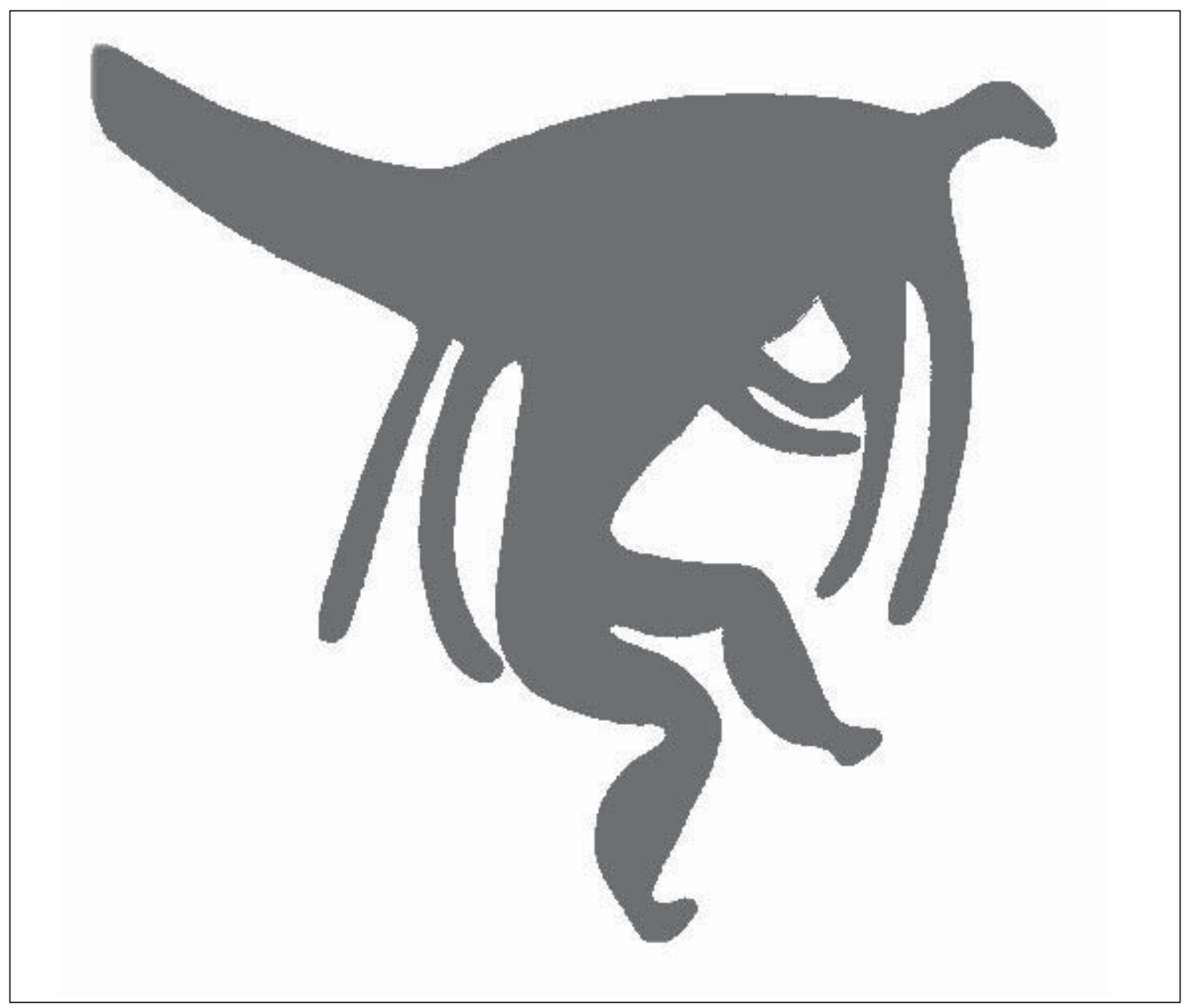

Figura 7. Mamar.

Orinar. No están presentes Echarse, Revolcarse y Bañarse, como tampoco fueron registradas en Lauca las actitudes de Sumisión, ni Morder (Huele-Muerde) que aparecen retratadas en las pinturas.

En segundo lugar, los porcentajes de frecuencia de cada actividad son diferentes en ambas muestras. Es así como Caminar y Correr aparecen con una frecuencia mayor en las pinturas (en Lauca con un $4.2 \%$ y un $0.4 \%$ respectivamente) mientras que en los paneles alcanzan un $13.5 \%$ y un $15.48 \%$. Por el contrario, Mamar presenta una frecuencia de $14 \%$ y Comer-Beber aparece con un porcentaje entre $83.9 \%$ y $88.9 \%$ en Lauca, siendo que en las pinturas la presencia de cada una de estas es de un $0.6 \%$ para ambas. La frecuencia de esta actividad en las pinturas es, por lo tanto, menor que en Lauca. Con respecto a las actitudes de Agredir-Jugar, en Lauca se registró un $4 \%$ de agresión y un $0.6 \%$ de juegos. En los paneles, en cambio, la presencia de actitudes agresivas alcanza un $15.4 \%$, un porcentaje mayor que en Lauca. Más aún, si se agregan las actitudes de Sumisión y Morder, el porcentaje de agresión alcanzaría a un $19.3 \%$.

A partir de estas observaciones puede decirse que en las pinturas rupestres se encuentran representadas actividades relacionadas con situaciones específicas de la vida cotidiana. Los animales fueron representados en actitudes de mayor movimiento, sin llevar a cabo su principal actividad que es comer, y con una elevada presencia de signos agresivos. En relación a esto, llama la atención el hecho de que dentro de la categoría Posturas no se detectaran situaciones predominantes. 
En efecto, en más del $50 \%$ de los casos no se observan posturas definibles, estando los animales en movimiento o quietos sin realizar actividades específicas.

Respecto a lo anterior, llaman también la atención las tendencias que se observan en las otras dos categorías: Cuello y Cola. Tal como se dijo antes, el Cuello Hacia Arriba es el atributo con el más alto porcentaje de frecuencia dentro de la categoría. En relación con esto, cabe mencionar que dentro de un grupo familiar, mientras las hembras y crías se dedican a comer, los machos se dedican a vigilar y cuidar, razón por la cual, entre otras cosas, el porcentaje que les corresponde en Lauca para la actividad Comer, es más bajo que para las hembras y las crías. El hecho de que todos los animales estén con el Cuello Hacia Arriba podría estar entonces indicando una situación de alerta. Si a esto se agrega el hecho de que los otros dos atributos observados, Cuello Hacia Atrás y Cuello Horizontal, son posiciones que por lo general indican molestia y agresión, se observa nuevamente una tendencia a graficar situaciones de conflicto.

Esto último se ve reforzado al revisar los resultados de la categoría Cola, donde el $63.1 \%$ de los casos está relacionado con estados de alerta o agresión. Es interesante destacar que la cola de tipo agresivo se da tanto en figuras quietas, como en figuras animadas.

\section{Conclusión}

Si bien los datos obtenidos en Parque Lauca corresponden a grupos familiares y es en las tropillas de machos solitarios ${ }^{4}$ donde la agresión es más recurrente, lo que hubiera dado un resultado más elevado para la presencia de esta conducta, creemos que en las pinturas rupestres del estilo Confluencia hay una intención de representar ciertos eventos y dejar de lado otros, y que dentro de estos se ha privilegiado el conflicto y la agresión.

Esto resulta interesante si se piensa que la agresión es la expresión de un instinto indispensable para la conservación y reproducción del grupo.

\footnotetext{
4 La presencia de una cría mamando en un panel del alero Aiquina (2-Loa 16) descarta la posibilidad de que se trate de grupos de machos (ver Figura 6).
}

Dentro de ese contexto, la principal función que esta cumple es la de mantener una distribución regular de los animales dentro del territorio, estableciendo la jerarquía en el grupo y organizando de esta manera el acceso de sus integrantes al alimento. En este sentido, la agresión es un comportamiento instintivo que ayuda a sobrevivir, porque organiza socialmente (Lorenz 1980). Esto, que ocurre entre las especies salvajes, se encuentra modificado entre las especies domesticadas. Es así como entre estas últimas la agresión es desviada en bien de la convivencia dentro de los hatos. Esta función de desviación es ejercida por el pastor, quien, al separar los machos de las hembras y los juveniles en edad de procrear, ejerce la función que le corresponde naturalmente al macho territorial (A. Glade, com. pers. 1996). Estas y otras funciones de la agresión, entre las cuales se cuenta su incidencia en la reproducción, hacen de ella un foco de interés tanto para la supervivencia del animal como para el observador.

De esta manera, en los paneles rupestres del estilo Confluencia queda en evidencia una línea común que une las distintas figuras representadas en torno a una idea relacionada con la agresión. La presencia de esta idea forma parte del imaginario de una sociedad en la cual está sugerida una cercanía entre el comportamiento de humanos y animales mayor de la que podrían sugerir las del estilo Cueva Blanca, donde los diseños geométricos siguen de cerca las convenciones iconográficas del diseño textil, bienes de prestigio andino, además de la notoria disminución y esquematización de las representaciones animales (Gallardo et al. 1999). En este sentido, el estilo Confluencia, asociado arqueológicamente a poblaciones aldeanas de patrón disperso y a horticultura y pastoreo de nivel doméstico, parece pertenecer a una época en la cual las relaciones, a pesar de los intercambios establecidos con poblaciones distantes como "el lago Titicaca, el sur de Bolivia y el noroeste de Argentina" (Gallardo et al. 1999: 67), se mantienen todavía dentro de un mundo conocido y pequeño. La preponderancia que adquiere la idea del conflicto en este imaginario es probablemente la expresión de un momento de cambio.

Agradecimientos A Carolina Agüero, Francisco Gallardo, Carole Sinclaire, Luis Cornejo, Pedro Mege. 


\section{REFERENCIAS CITADAS}

ALDUNATE, C., J. BERENGUER, V. CASTRO, L. CORNEJO y C. SINCLAIRE, 1986. Cronología y asentamiento en la región del Loa Superior. Dirección de Investigación y Bibliotecas, Universidad de Chile, Santiago.

BERENGUER, J., 1995. El arte rupestre de Taira dentro de los problemas de la arqueología atacameña. Chungará 21 (1): 7-43.

BERENGUER, J., C. ALDUNATE, V. CASTRO, C. SINCLAIRE y L.CORNEJO, 1985. Secuencia del arte rupestre en el Alto Loa: Una hipótesis de trabajo. En Estudios en Arte Rupestre, C. Aldunate, J. Berenguer y V. Castro (Eds.). pp. 87-108. Museo Chileno de Arte Precolombino, Santiago.

BERENGUER, J. y J. L. MARTINEZ, 1989. Camelids in the Andes: Rock art environment and myths. En Animals into Art, H. Morphy (Ed.), pp.390-416. One World Archaeology 7 , Londres.

FRANKLIN, W. L., 1982 a. Contrasting socioecologies of South America's wild camelids: The vicuña and guanaco. En: Recent advances in the study of mammalian behavior. American Society of Mammalogists 7, Special publication. J. Eisenberg y D. Kleiman (Eds.), pp. 573-629, Pittsburg.

-1982b. Lama language: Modes of communication in the South American camelids. Llama World 7: 5-12.

GALLARDO, F., 1996 Ms. Informe de avance Proyecto FONDECYT 1950101, Santiago.

-2001. Arte rupestre y emplazamiento durante el Formativo Temprano en la cuenca del río Salado (desierto de Atacama, norte de Chile). Boletín del Museo Chileno de Arte Precolombino 8: 81-95.

GALLARDO, F., C. SINCLAIRE y C. SILVA, 1999. Arte rupestre, emplazamiento y paisaje en la cordillera del desierto de Atacama. En: Arte rupestre en los Andes de Capricornio, J. Berenguer y F. Gallardo (Eds.), pp. 57-96. Museo Chileno de Arte Precolombino, Santiago.

GONZALEZ, P., en prensa. Códigos visuales en las pinturas rupestres de la Subregión río Salado, norte de Chile. Monografías del Museo Chileno de Arte Precolombino 1.

GLADE, A., 1982. Antecedentes ecológicos de la vicuña (Vicugna vicugna) para su manejo en el Parque Nacional Lauca, Primera Región, Chile. Tesis para optar al grado de médico veterinario, Universidad de Chile, Santiago.
GLADE, A. y P. E. CATTAN, 1987. Aspectos Conductuales y reproductivos de la vicuña. $\mathrm{H}$. Torres (Ed.) Unión para la conservación de la naturaleza y sus recursos/Programa de las Naciones Unidas para el medio ambiente, Santiago.

KOFORD, C. B., 1957. The vicuña and the puna. Ecological Monographs 27: 573-629.

LE PAIGE G., 1958. Antiguas culturas atacameñas en la cordillera chilena. Anales de la Universidad Católica de Valparaíso 4-5: 1-14.

LORENZ, K., 1980. Sobre La agresión, el pretendido mal. $9^{a}$ edición, Siglo XXI, México D. F.

1986. Fundamentos de la etología. Paidós Studio Básica, Buenos Aires.

MEGE, P., en prensa. Herramientas semiológicas para el análisis e interpretación de la pintura rupestre. Monografías del Museo Chileno de Arte Precolombino 1.

MONTT, I., en prensa. Elementos de atuendo e imagen rupestre en la Subregión río Salado, Norte Grande de Chile. En Actas del XV Congreso de Arqueología Chilena, Arica, 2000.

MOSTNY, G. y H. NIEMEYER, 1983. Arte rupestre chileno. Ministerio de Educación, Serie Patrimonio Cultural Chileno, Santiago.

NIEMEYER, H., 1972. Las pinturas de la sierra de Arica. Editorial Jerónimo de Vivar, Santiago.

NUÑEZ, L., 1994. Emergencia de complejidad y arquitectura jerarquizada en la Puna de Atacama: Las evidencias del sitio Tulan-54. Taller de costa a selva: Producción e intercambio entre los pueblos agroalfareros de los Andes Centro Sur, M. E. Albeck (Ed.), pp. 85-116. Instituto Interdisciplinario Tilcara, Tilcara.

SHANKS, M. y C. TILLEY, 1987. Social theory and archaeology. Polity Press, Londres.

SINCLAIRE, C., 1997. Pintura rupestre y textiles formativos en la región atacameña: Paralelos iconográficos. Estudios Atacameños 14: 327-338.

TACON, S., 1989. Art and the essence of being: Symbolic and economic aspects of fish among the peoples of Western Arnhem Land, Australia. En Animals into art, H. Morphy (Ed.), pp. 236-250. One World Archaeology 7, Londres. 